\title{
DEL SER PARA LA MUERTE AL SER CONTRA LA MUERTE. UNA RECONSIDERACIÓN DEL VITALISMO HIPERBÓLICO DE EMMANUEL LÉVINAS*
}

\author{
FROM BEING TO DEATH THROUGH BEING AGAINST DEATH. \\ A REVIEW OF EMMANUEL LÉVINAS'S HIPERBOLIC VITALISM
}

Patricio Peñalver Gómez ${ }^{* *}$

\section{Resumen}

Partimos de una revisión crítica de la interpretación canónica del tema platónico del cuidado de la muerte propia como condición típica del filósofo: el Fedón no propone algo así como una "preparación a la muerte", sino más bien una resistencia intensamente reflexiva del alma frente al proceso natural de la muerte. Entendemos que la fenomenología heterológica de Lévinas permite formalizar este vitalismo hiperbólico de raíz platónica a través de la categoría del "ser contra la muerte", en sistemática polémica con el famoso "ser para la muerte" de Heidegger. Lévinas permite una comprensión filosófica del natural "miedo a la muerte" de todo ser vivo: el permanente "aplazamiento" de la última hora da tiempo y posibilidad a un Deseo del Otro, impensable en cambio en las coordenadas del solipsismo existenciario heideggeriano.

\section{Palabras clave}

"Ser para la muerte", "ser contra la muerte", "aplazamiento".

Artículo investigación para este número monográfico.

** Docente Universidad de Murcia (España). 


\begin{abstract}
We start whith a critical review of the canonical interpretation of the Platonic theme of caring for the one's own death as a condition typical of the philosopher: the Phaedo does not propose something like a "preparation for death", but rather an intensely reflective soul resistance against the natural process of death. We understand that the heterologic phenomenology of Lévinas enables to formalize this hyperbolic vitalism Platonic roots through the category of "being against the death" in systematic controversy with Heidegger famous "being for death" from Lévinas allows a philosophical understanding of the natural "fear of death" of all living things: the permanent "stalling" in the last hour gives time and opportunity to a desire of the Other, unthinkable though in the coordinates of Heidegger's Existential solipsism.
\end{abstract}

\title{
Key words
}

"Being toward death", "be against the death", "postponement".

\section{La melete thanatou, 0 "hacerse el muerto" como método}

El tópico que establece una afinidad básica entre el ejercicio de la filosofía y la experiencia de la muerte tiene sin duda un fundamento múltiple ${ }^{1}$. Reconocible éste ya intuitivamente en dos planos: tanto en la complejidad histórica de las formas de pensamiento que se generan a partir de la "ciencia primera" de los Griegos, como también en el vínculo esencial, "estructural", que cabe identificar en el sistema mismo de la filosofía. La especulación primera sobre el ser de los físicos milesios es indisociable de una consideración específicamente racionalista, "calculadora" incluso, de los procesos de generación y corrupción. El Sein zum Tode de Heidegger, pero también el silencio ante el límite de Wittgenstein (y por recordar justamente dos idiomas filosóficos, dos Stimmungen tan disparatadamente alejadas), atestiguan que, por cierto que a través

1 Me permito reescribir y ampliar aquí el texto que utilicé como guión para la conferencia impartida en el ciclo "Lecturas de la muerte", en la Biblioteca Regional de Murcia, el 15 de octubre de 2007. de mil trasformaciones y giros, el lazo indesligable entre filosofía y muerte, entre "la" filosofía y cierta manera de relacionarse con la muerte, vuelve a encontrarse en el centro mismo del pensamiento occidental en su fase tardomoderna. A través de formas históricas muy diversas cabría identificar una constante sistemática o quasi-sistemática: la de que "la" filosofía supone o más bien incluye una peculiar reflexión sobre el no-ser, sobre la destrucción, y sobre la muerte.

Sin embargo, hay que matizar, si es que no rectificar, la tendencia interpretativa dominante en relación con el tópico de los negocios de la filosofía con la diversa experiencia del morir. No se trataría aquí, o más bien al contrario, de asociar aquel vínculo a la invocadísima presunta afinidad de la filosofía perenne con cierto pensamiento edificante de la fugacidad del día y con los prestigios de una cierta meditatio mortis.

Una pertinaz leyenda que enseguida vamos a querer zarandear atribuye a Platón mismo el vulgarísimo nihilismo, virulento en buena parte de la sedicente alta cultura, y que asocia la filosofía como tal a la meditación edificante de la vanidad de lo que nace, pasa, y muere. Con vacía solemnidad frecuentemente se 
asigna a la gravedad del filósofo una especial preocupación por el abismo entre el viviente y la Noche, o, por decirlo con el visitadísimo rilkismo al que tan aficionada es una insufrible típica "alta cultura", la demanda de una "muerte propia". No hay porqué verlo así. Más bien al contrario. $\mathrm{O}$ al menos vamos aquí a proponer formalmente que la relación esencial de la filosofía y la muerte a lo que justamente apela es a una especie de resistencia reflexionada frente a la muerte. Y por lo pronto frente a la "propia", claro.

De manera que la afinidad de la filosofía con la muerte se manifiesta, cuando menos, a veces, en un enfrentarse con la muerte como drama, crisis, escándalo incluso. La filosofía -en contra así de su legendaria tarea de "tranquilizadora" ante lo inevitable- debe hacerse cargo del profundo "no aceptar la muerte" del viviente más o menos sano. Tampoco claro está la de otros. Decía el último Derrida que la muerte del otro no es "sólo" la desaparición de tal o cual vida, sino "cada vez el fin del mundo en su totalidad, el fin de todo mundo posible, y cada vez el fin del mundo como totalidad única, y así irreemplazable, y así, infinita" (Derrida, 2001, p. 9).

"Ser contra la muerte" es expresión literal -y sin duda algo chocante, voluntariosamente provocadora- precisamente del eminente filósofo judío francés de origen lituano, Emmanuel Lévinas, en el que hoy queremos interesarnos. Se encuentra dicha expresión en su explicación acerca de la estructura de la voluntad, en el marco de su tratado más sistemático (Totalidad e infinito). Puede esperarse ya de esos términos: una articulación decisiva de esa explicación requiere una inversión de la famosa tesis finitista y tragicista de Heidegger que tanto ha dado que pensar durante decenios. Hasta el enemigo acérrimo del filósofo de la "jerga de la autenticidad" que fue Adorno reconocía al menos indirectamente la importancia del capítulo sobre el ser-hacia-la-muerte de Ser y tiempo. Y entre nosotros, Felipe Martínez Marzoa ha replanteado últimamente la relevancia del motivo de la muerte en el "pensamiento esencial" (Adorno, 1975, pp. 101-139; Marzoa, 1999).

Pero lo que aquí andamos buscando es una inversión, o, a decir verdad, un enérgico desplazamiento respecto de la rocosa ontología de la temporalidad finita del Dasein en el análisis existencial. A ese enclave polémico volveremos luego temáticamente. Pero en primera instancia, y muy concretamente para tomar distancia desde el primer momento en relación con la presuntamente filosófica "meditación de la muerte", sugiero que atendamos a la parte de verdad que sin duda se alberga en el famoso, y bello alegato vitalista de Espinosa: "Un hombre libre en nada piensa menos que en la muerte, y su sabiduría no es una meditación de la muerte, sino de la vida" (Ética, V, proposición 67).

No la melancolía, negra como la propia palabra lo dice, sino la alegría es la Stimmung básica de la filosofía. Un Diccionario de Filosofía empezará con esa voz, y no sólo por el motivo alfabético obvio. Fernando Savater lo dijo con gracia (Savater, 2000), en la estela del risueño Sefardita de Ámsterdam, creador, suele reconocerse, de una de las dos o tres formas "eternas" (a partir de la matriz "estoicismo ateo de raíz cristiana") del racionalismo occidental. Y a su manera avala esto Hollywood: desde la capital de la industria de la diversión se nos recuerda de vez en cuando que "la muerte puede esperar".

Menos inmediatamente verosímil parece que pueda invocarse a Platón como precedente de la idea de la filosofía como resistencia a los poderes de la muerte. Pero el caso es que sí, $\mathrm{y}$, al menos tentativamente -no va a ser hoy nuestro tema principal-, queremos sugerirlo inicialmente. Cabe hacerlo a partir de una lectura no convencional del texto 
supuestamente canónico de la filosofía como "preparación para la muerte" en el Fedón. En efecto, en aquel movimiento filosófico enfáticamente vitalista que evocábamos hace un momento, en aquella peculiar resistencia de la inteligencia filosófica a la tópica melancólica "preparación" de la muerte, cabría incluir la famosa melete thanatou, el "cuidado de la muerte" que el Platón del Fedón atribuye al filósofo por antonomasia.

En contra de la interpretación hiperbólicamente vitalista de la melete thanatou que quisiera esbozar parece hablar ciertamente por lo pronto el motivo literal visitadísimo de que la dedicación a la filosofía implica sobre todo una ocupación prioritaria, si es que no única, "en morir y en estar muerto" (64 a). Para sugerir una lectura como la que ahora buscamos -digamos, Platón "contra" la filosofía resignada del consciente moriturusse impone, parecería, una cierta violencia interpretativa, una demasiado strong reading. Más bien lo que se reclama aquí es un nítido desplazamiento respecto de la interpretación convencional de la preparación filosófica ante la muerte apud Platón en términos de tranquilo, protoestoico, acatamiento del fin inevitable, tras una larga y metódica ejercitación de separación del alma y el cuerpo ya en la vida.

El relato de las últimas horas de la existencia de Sócrates en serena conversación filosófica con sus amigos quiere y debe subrayar la continuidad entre la existencia cotidiana y la vida a las puertas de la muerte. Sócrates no tiene por qué cambiar ante la proximidad previsible del fin de su vida: justo porque el filósofo ya en su cotidianidad, a lo largo de su existencia, habría interiorizado, más bien ejercido, la preparación para la muerte. En doble y complementaria dirección: ascéticamente, separando el alma del cuerpo, e intelectualmente, separando lo sensible y lo inteligible. El verdadero filósofo piensa valientemente ("virilmente": la llorosa y quejosa Jantipa debe marcharse de allí): habla, inquiere-aquí por ejemplo sobre la naturaleza y el destino del alma, que en efecto va a ser el "tema" del diálogo-, como siempre lo ha hecho, también en las últimas horas de su vida. En fin, con algún “escrúpulo” suplementario. De siempre Sócrates recibía en sueños la orden divina de "hacer música". Para el prosaico y rústico Sócrates, hasta unos días antes de su prevista muerte, la orden del dios de "hacer música" sólo podía significar "hacer filosofía”. Ahora Sócrates, por si acaso, se plantea la posibilidad de una interpretación literal del sueño: en consecuencia ha compuesto un poema de base esópica. Pero al margen de ese escrúpulo "religioso" o, si se quiere, de esa concesión a la piedad, lo esencial de la actitud socrática en el inicio del diálogo reside en la reafirmación de una coherencia existencial: el filósofo verdadero filosofa a las puertas de la muerte como siempre lo ha hecho.

Bosquejo una aproximación al primer movimiento del relato de Fedón a Equécrates (58 a-69 e), formalmente preliminar, y que antecede al inicio de la inquisición propiamente dialéctica de la controvertida esencia del alma y de su problemático destino. Este destino suscita en la gente "mucha desconfianza" (70 a), en el trance de la muerte. Destacamos dos motivos mayores en esta reflexión canónica sobre la relación del sabio ante la última hora, ante "su" última hora. Hay primeramente una exploración del aplazamiento. A partir del concretísimo aplazamiento del cumplimiento de la sentencia en el caso de Sócrates (hay que esperar a que retorne a Atenas la nave de Delos, la procesión náutica en homenaje a Teseo durante la cual las normas de purificación prohíben la ejecución de los condenados), se perfila en la meditación platónica la posibilidad típica de un aplazamiento "esencial" en la relación de todo viviente con su final. La importante condena formal del suicidio tiene su lugar aquí. El segundo motivo es el de la 
melete thanatou que venimos evocando, el cuidado de la muerte. Anticipo la interpretación de dicho motivo, en polémica con la lectura convencional (preparación del filósofo para el viaje ultramundano, y consecuente "serenidad" del sabio en el último trance): cuidar la muerte sería, más bien, en última instancia "hacerse el muerto". Estaríamos ante un método filosófico, o si se quiere, ante una condición existencial, y hasta corporal, para el ejercicio del método filosófico de conocimiento: neutralizar los afectos y los intereses, llevar hasta la hipérbole la tendencia de toda alma a la objetividad y a la verdad.

Sócrates envía a Eveno de Paros, a través de Cebes, un muy ambiguo saludo: a aquel sofista que se había interesado en los negocios musicales de Sócrates, a la vista de su último trance le trasmite que, "si es sensato", le siga lo antes posible en su viaje al otro mundo. Simmias protesta: Eveno no querrá. Ahora bien, replica Sócrates, "si es filósofo", estará dispuesto a seguir al que muere. Y sin embargo, esa disposición típicamente filosófica a emprender el viaje afuera de este mundo, no ampara, como podría quizá pensarse, el suicidio. Es aquí donde se aloja el motivo del aplazamiento. Al menos cabe entender que hay aplazamiento allí donde expresamente se prohíbe la "precipitación", el hacerse violencia para acceder a la esfera de la "verdad" (o cuando menos para rasgar el velo que supone habitar al fondo de la caverna, rodeados de sombras). Sócrates parece buscar la complicidad con sus interlocutores Simmias y Cebes, pertenecientes al círculo pitagórico de Filolao de Crotona, quien, se dice, declaraba formalmente ilícito el suicidio. Una primera justificación de esta condena del suicidio, cualificada por Platón como "grandiosa", pero oscura, "difícil del entender", invoca la metáfora órfica de la prisión: "los humanos estamos en una especie de prisión, y (...) no debe uno liberarse a sí mismo ni escapar de ésta" (62 b). Se impone aquí la resonan- cia, el eco de una concretísima negativa de Sócrates a escaparse de la prisión, a lo que Platón dedica una meditación importante en el Critón. Pero hay que justificar mejor la ilicitud del suicidio: es que "los dioses son los que cuidan de nosotros y que nosotros, los humanos somos una posesión de los dioses" (62 b). Digámoslo ya: Lévinas incorpora al pensamiento heterológico, a su "argumento de alteridad", este motivo de la prohibición formal del suicidio. Pero esta prohibición no es, o no es ante todo, de tipo religioso: se encuadra más bien en la resistencia filosófica a la muerte, en el combate contra el acosmismo tendencial del melancólico o del "sabio" que quiere alejarse de este mundo. "Sócrates, al condenar el suicidio, al comienzo del Fedón, se niega al falso espiritualismo de la unión pura y simple e inmediata con lo Divino, calificada de deserción. Proclama ineluctable la marcha difícil del conocimiento que parte de este mundo" (Lévinas, 1976, p. 72.)².

Ahora bien, argumenta Cebes, si esto es así, si el cuidado divino ampara nuestra "vida", se hace tanto menos comprensible que los filósofos quieran morir, quieran, esto es, dejar de estar bajo el cuidado de los dioses (62 cd). Eveno tendrá toda la razón en no querer acompañar a Sócrates. Que acoge con regocijo la afición elenctica de su amigo (62 e). Parece absurdo, "no tiene explicación", esa disposición de los filósofos a morir que aquí en concreto Sócrates "ofrece" a Eveno. No tiene razón de ser el que "no se irriten los (hombres) más sensatos de dejar esa situación de servicio, en la que les dirigen quienes son los mejores dirigentes que existen, los dioses" (62 d). El filósofo que sabe que los

2 El contexto remite a una formal reivindicación del intelectualismo griego, en la base del racionalismo filosófico occidental, en cuyo marco en última instancia habría que colocar la metafísica de la alteridad. Sobre el suicidio, instructivo el "radicalismo" de la posición de Paul Louis Landsberg. (Landsberg, 1999). 
dioses ordenan y amparan la vida humana no debería nunca estar dispuesto a la muerte, y menos todavía "quererla".

En respuesta al argumento de Cebes se requiere nada menos que una nueva apología (63 b), con la esperanza de que esta vez la defensa o la autodefensa del filósofo resulte más convincente que ante los jueces. Pero aquí Sócrates no defiende la legitimidad y, finalmente, la misión divina, de la existencia que se examina a sí misma (y somete también a implacable escrutinio la existencia de los demás) en la muy peligrosa Atenas. Aquí lo que Sócrates defiende es que es propio del filósofo el cuidado de la muerte, la melete thanatou.

En el inicio de esta nueva apología, Sócrates señala un equívoco profundo en la relación entre la gente vulgar y el filósofo: el vulgo está convencido de que a él no le pasa "inadvertido" en qué sentido los filósofos "no se cuidan de ninguna otra cosa sino de morir y de estar muertos" (64 a). Simmias parece asentir risueñamente: en efecto, la gente vulgar interpreta que "los que filosofan andan moribundos", y además, a la gente, a los demás, "no se les escapa" que aquellos filósofos son dignos de sufrir tal muerte. Me atrevería a sugerir que la interpretación al mismo tiempo dominante y rutinaria de la melete thanatou se desliza alucinadamente por la vía de lo denostado por Platón como representación vulgar, vehiculada aquí por Simmias. El caso es que Sócrates marca nítidamente una distancia entre dicha representación vulgar del filósofo enfermo de muerte, y la relación con la muerte pensada filosóficamente. De manera que hay que "mandar a paseo" al vulgo, conversar "entre nosotros sólo" (64 c).

Y "entre nosotros", la relación del filósofo con la muerte coincide con la liberación del alma para el conocimiento, con una liberación del deseo de lo real: el alma recogida en sí misma, en la medida en que neutraliza sentidos y sensaciones, "tiende hacia lo existente" (oregetai tou ontos) (65 c). Ejercitarse en la muerte equivaldría a una neutralización de los afectos y de los intereses pragmáticos, una liberación de la filosofía que de hecho implanta ésta en el "tiempo libre" de la gente libre, en la sjolé (66 d). De manera que el verdadero sentido de la disposición del filósofo ante la muerte -ese sentido que "le pasa inadvertido" al vulgo- es la ruptura con el interés pragmático típico de la experiencia cotidiana, "corporal". La melete thanatou consistiría entonces como dije hace un momento, y si se nos permite un cierto juego en la invención interpretativa, en "hacerse el muerto", en paralizar metódicamente nuestros lazos mundanos, eventualmente para conocer mejor la naturaleza de nuestros lazos mundanos. Hacerse el muerto, metódicamente o astutamente, (y acaso sería ejemplo mayor de esto la estrategia formalmente apolítica o despolitizadora de Sócrates en su "obediencia al dios", orientada expresamente a evitar una muerte precoz del filósofo testigo de la verdad $^{3}$ ), permitiría entonces profundizar en el vitalismo profundo de la filosofía, y así en su resistencia a la oscuridad de la muerte, si se sigue nuestra inquietud. Platón no propone aquí entonces nada parecido a la protoestoica serenidad del sabio imperturbable ante la perspectiva de tener que abandonar este mundo o desaparecer. El "ejercitarse en la muerte" es otro nombre del método filosófico, del conocimiento de la esencia. Esos términos indican un estilo típico de existencia (el alma

3 En la Apología, Sócrates justifica formalmente su apoliticismo, en un Estado que fustiga la opción vital por "lo privado", sobre la base de consideraciones muy realistas: si hubiera entrado en política, habría muerto joven. Platón se esfuerza en poner a igual distancia a su admirado iniciador respecto del régimen democrático (a propósito del juicio ilegal de los estrategas de la batalla de las Arginusas), y respecto del régimen oligárquico (la coerción a los ciudadanos para implicarlos en los crímenes de Estado). 
se ejercita "continuamente" en la concentración en sí misma, 80 e), un estilo que consiste para el alma "en ejercitarse en estar muerta con soltura (radios)" (81 a).

Señalemos un contexto especialmente relevante para esta sugerencia interpretativa de que la melete thanatou debe entenderse en las antípodas de la melancólica meditatio mortis, o más bien que debe asociarse finalmente al hiperbólico amor a la vida del sabio que en nada piensa menos que en la muerte.

Vivísimas, en verdad, y desde luego "mundanas", son las "almas muertas" del bello mito del juicio final, al final del Gorgias (523 a-527 a). La letra del relato remite a una escena ultramundana, cierto. Pero el sentido absolutamente "realista", "mundano" de esa narración -que "ilustra" el argumento central del diálogo: que es mejor sufrir la injusticia que cometerla, y que es mejor ser juzgado que permanecer impune- nos parece transparente. Con el paso del régimen judicial de la época de Cronos al de la época de Zeus, Platón apunta a la necesidad de una reforma legal en Atenas. Que estén muertos, y desnudos, y tanto los jueces (Minos, Eaco y Radamante, en el relato mítico), como los juzgados -y tal es la novedad del derecho procesal del tiempo de Zeus respecto al de Cronos-, tiene el sentido de que sólo así se cumple la condición de absoluta objetividad del juicio. Juez y juzgado se ven cara a cara: desnudos. Y "muertos": sin duda en el sentido de "sin intereses", ajenos a toda posibilidad de pasión parcial. Pero también en el sentido de ineluctabilidad de la responsabilidad por los propios actos, y así, en completa inversión del esquema mítico del destino.

La forma específicamente filosófica de resistirse a la muerte que atestigua al menos un estrato del platonismo (la responsabilidad del conocimiento frente al delirio místico, por ejemplo el de estirpe órfico-pitagórica) está a su vez implantada en una tendencia profunda de la cultura griega. Aunque inmerso en el mundo de la generación y la corrupción, el viviente se niega a aceptar la muerte. La "verdad" de la muerte se capta en la resistencia a la muerte de un ser que quiere durar en el tiempo. En el miedo a morir, y por ejemplo en el "verde miedo" de Ulises en la Neikía, durante la visita a la región de los muertos que rinde el héroe de Ítaca, habría un núcleo cognitivo. Puede leerse así, en esta perspectiva, todo el libro XI de la Odisea. Y acaso la más enérgica protesta de un muerto contra su "situación" espectral en la literatura occidental es la célebre de Aquiles que habla con claridad: mejor ser el último esclavo de un porquero en su tierra, que rey en el reino de las almas o las sombras.

Un paso poco visitado de Aristóteles deja ver una plena autoconciencia de los griegos como pueblo de la existencia terrestre, en contraposición a la cultura tanática por antonomasia en la época antigua, los egipcios. Aristóteles recuerda el motivo abiertamente utilitarista de Sócrates: apartamos las cosas inútiles, incluso aquellas que son en principio partes de nosotros mismos, como el pelo, la saliva, las uñas. En esa serie - cosas inútiles a desecharhabría que situar, continúa Aristóteles, ciertamente algo menos piadoso aquí que el griego medio, los cadáveres. Desechamos, en efecto, “el cuerpo cuando muere, pues el cadáver es inútil. Pero aquellos para quienes es útil lo conservan, como en Egipto" (Ética Eudemia, VII, 1235 b 1-3). (Queda indeterminada la posibilidad de un eco de ironía ante el tanatismo egipcio en este pasaje, pero, como se sabe, el tropo en cuestión transita con dificultades en el elemento de la escritura. La potencia del texto platónico para trasmitir la ironía socrática debe reconocerse como un signo de la genialidad del primer filósofo escritor. Y sin duda, no superado en esa dimensión, filósofo que escribe, y consigue "enseñar" entre las líneas (Peñalver, 1987)). 
Podría quizá querer aducirse, contra esta "unilateral" mirada a los Griegos amantes de la existencia terrena, la aparente presencia del motivo del amor fati. Lo cierto es que el Estoicismo -llamado a adquirir un peso tan significativo en la cultura europea, y que formaliza ese tema, y proyecta en el hecho de la muerte el esquema salvacionista del individuo que se integra en la Totalidad-no tiene raíz griega genuina. Desde hace tiempo (Brehier, Elorduy), buena parte de la historiografía ha señalado el carácter irreductiblemente asiático del fenómeno estoico.

\section{Insistencias de la muerte en el itinerario de Lévinas}

Es el propio Lévinas más sistemático, el de Totalidad e infinito, el que nos daba pie a comenzar por esta tentativa de invertir la orientación de la interpretación dominante de la melete thanatou del Fedón. Lo decisivo en las reflexiones iniciales de Sócrates en ese diálogo, en el contexto de la tesis del filósofo que "cuida" su relación con la propia muerte, no sería la fortaleza o la serenidad, sino la responsabilidad hiperbólicamente vital frente a toda tentación de "huir" de esta existencia, mediante el suicidio, o mediante algún salto místico a lo "divino". El Lituano apunta, veíamos, en esa dirección en aquella obra. Por nuestra parte apenas hemos hecho otra cosa que ampliar las referencias textuales e indicar los motivos que confirman aquella interpretación.

Pero es la propia filosofía de Lévinas en algunos de sus motivos más característicos la que queremos describir aquí, con vistas a que se advierta su virulencia como dispositivo teórico para una tentativamente novedosa "lectura de la muerte".

Sin comprometernos ahora en una "teoría" sobre la evolución de la filosofía de Lévinas (Sucasas, 2004; Peñalver, 2000) -y en concreto sobre el alcance de la "coherencia" esencial de su itinerario, o sobre la mayor o menor discontinuidad entre las etapas de una trayectoria en cualquier caso larguísima en el tiempo, entre el precoz lucidísimo ensayo sobre el hitlerismo de 1934 (Lévinas, 1998), y el último volumen de la serie de estudios talmúdicos publicado pocos días después del fallecimiento del autor (Lévinas, 1996)-, cabe al menos aquí distinguir tres momentos. Hay en los escritos publicados en la inmediata Posguerra una primera irrupción del tema de la muerte, que debe asociarse a la progresiva percepción de los límites de la forma dominante (idealista, "totalista", tautologista) de la filosofía occidental. Sin duda debió jugar un papel en esto la primera lectura de Rosenzweig en los últimos treinta años. Del filósofo de Cassel se recordarán las impresionantes páginas iniciales de la Estrella de la redención escritas en el frente turco de la Gran Guerra, en las que se da voz al hombre "sano", resistente a los cantos órficos de la filosofía:

No queremos una filosofía que vaya en el cortejo de la muerte y con el acorde de su danza (Uno y Todo, Uno y Todo) nos haga olvidar el dominio perdurable de la muerte. No queremos engaño alguno. Si la muerte es Algo, en adelante ninguna filosofía ha de hacernos apartar de ello la vista, afirmando que presupone Nada (Rosenzweig, 1997, p. 45.).

En segundo lugar, nos interesaremos en formalizar el elemento existencial pero también cognitivo que "la" obra sistemática por excelencia, Totalidad e infinito (1961) asigna a esa estructura típica de la voluntad que es el "ser contra la muerte". En fin, en tercer lugar, querré localizar los momentos en buena medida polémicos del último curso de su enseñanza universitaria, impartido por el Lituano en 1975 y 1976, y titulado "La 
muerte y el tiempo" (Lévinas, 1993). Lo "adquirido" en el libro del 61, será en este último magisterio, base para nuevas exploraciones, en diálogo con algunas de las más instructivas explicaciones filosóficas de la relación con la muerte.

\section{La filosofía de Shakespeare y el combate contra los mercaderes de la angustia}

La serie de cuatro conferencias dictadas en 1946 por Lévinas en el Collège Philosophique (fundado por Jean Wahl en pleno Quartier Latin en un clima histórico marcado por la Liberación, y por un existencialismo militante y revestido de fácil conciencia de vanguardia) se publicaron inicialmente en un volumen colectivo de título muy indicativo del contexto, y de la época en general: $L a$ Elección, el Mundo, la Existencia. Reeditadas muchos años después como libro propio ${ }^{4}$, la base escrita de aquellas conferencias constituye seguramente el texto más exotérico del filósofo judío. Se entiende que se recurra a ellas para fines introductorios. Pero la accesibilidad de las doctrinas de esa obra tiene, sin duda, su parte de sombra: una "comprensible" generalidad si no simplicidad en los movimientos del análisis. Propongo, sin embargo, que recurramos a la "claridad" de la propuesta de ese ensayo, como primer paso.

El tiempo y el Otro remite a un contexto polémico inmediato, visible ya en las líneas del

$4 \quad$ Lévinas, 1979. El prefacio a esta reedición marca las distancias del Lévinas que ha alcanzado ya una clarificación metódica y sistemática de su pensamiento, respecto de estos esbozos destinados inicialmente a una cierta improvisación oral. La traducción española (El tiempo y el otro, Paidós, 1993) se enriquece con una original introducción de Félix Duque. Quede abierto si el esquema interpretativo de una categoría como "mazdeísmo neorromántico", y aunque bajo interrogantes, puede ser efectivo para registrar la aportación Lévinasiana al tema erótico. texto, pero quizá más determinante de lo que habitualmente asume el movimiento tendencial de la lectura de cualquier libro, sobre todo si revestido éste con la autoridad de un "pensador" reconocido. En esa tendencia, el libro queda recortado, aislado de la trama existencial e histórica de la que nace: deviene abstracto objeto exento, eventualmente exquisito. Convendría particularmente en este caso invertir dicha tendencia. El objeto principal de las conferencias es una exposición fenomenológica de la estructura intersubjetiva del tiempo. Pero hay que ver cómo Lévinas despliega su tesis en combate con el existencialismo, a su vez militante, de buena parte de los asistentes a las conferencias. Creo que se pierde la "gracia" del texto si no se recuerda "a quienes" y hasta "contra quienes" se plantea la tesis de que la verdad del tiempo es la alteridad. Esa tesis se plantea "contra" la seguridad estabilizada de la buena nueva triunfante -en la moral y en la política de la clase dominante del París de Posguerra-: el decisionismo desarraigado de Monsieur Pour-soi, el tragicismo abstracto del primer Sartre, en confusa relación a su vez éste con el análisis ontológico del Heidegger de Sein und Zeit ${ }^{5}$. Confusa, e influyente: Sartre avaló durante decenios la traducción de Dasein por "realité humaine".

Lévinas zarandea el existencialismo en sus dos formas dominantes, la de Heidegger y la del francés, a partir de una alternativa específicamente filosófica (técnicamente fenomenológica) que osa, en la estela de Rosenzweig, "romper con Parménides" (Lévinas, 1979, p. 20). (Pero al de Cassel no se le menciona en el texto, sin embargo, puede entenderse la cautela o la discreción: sin duda reconocer esa herencia habría confirmado

5 Se puede reconocer ya en el Lévinas de $D e$ la existencia al existente (trad. esp. en Arena Libros, 2000) una toma de distancia respecto al ontologismo de Heidegger. Acerca de la relación entre Lévinas y Sartre, Peñalver, 2006, pp. 99-135). 
los más rápidos diagnósticos apotropaicos de los oyentes y lectores de la época, desde el tranquilo rechazo de la posibilidad de algo así como una filosofía a partir de fuentes judías). Pero hay un momento moral y político, pre-filosófico, si se quiere, en la mirada Lévinasiana a la filosofía abrumadoramente dominante de aquella hora. Aunque el tropo ironía funciona ante todo en el lenguaje oral, aquella resuena todavía en la lectura silenciosa de este trozo:

En medio de las angustias pascalianas, kierkegaardianas, nietzscheanas, y heideggerianas, nos conducimos como horribles burgueses. (...) Puede uno pensar que el tiempo auténtico es originalmente un éxtasis, pero compra uno un reloj; a pesar de la desnudez de la existencia, en la medida de lo posible, hay que estar decentemente vestido. Y cuando se escribe un libro sobre la angustia, se lo escribe para alguien, se pasa a través de todos los pasos que separan la redacción de la publicación, y se conduce uno, a veces, como un mercader de angustia (Lévinas, 1979, pp. 41-42; mío el énfasis).

La nada neutra "neutralidad" ontológica de Heidegger, su "decisión" de un primado del Ser que no es nadie sobre el existente que es alguien, impide la liberación de una fenomenología del tiempo como alteridad, una posibilidad filosófica que requiere, en aparente paradoja, la previa profundización en la soledad del existente (lo que llamará Lévinas más tarde, la "separación", el "ateísmo" del yo). La presunta revolución intelectual de la pregunta por el Ser (ya no pregunta por el ente, según la insistencia monótona del alemán) está a pesar de todo incluida en la continuidad de la tradición de la tendencia dominante en la filosofía occidental: continúa la Ontología, reitera la primacía del concepto, de la totalidad, y de la categoría de lo Mismo.

Pero también el existencialismo de rostro humano del autor de El ser y la nada sigue a su modo preso del "idealismo clásico" (Lévinas, 1979, p. 43), y esto significa aquí: incapaz de la liberación fenomenológica de la mirada a las cosas (diríamos hoy con palabras de Miguel García Baró: incapaz de la "actitud fenomenológica" y de su "arte": "aprender a ver las cosas a las que la vida está ya mirando”)(García Baró, 1998). Éste relativamente poco conocido Lévinas del 47 tuvo la audacia de señalar un "angelismo" en la base del impensado "presentismo" del existencialismo sartreano: "Hay en la filosofía de Sartre un no sé qué presente angélico. Al quedar arrojado al pasado todo el peso de la existencia, la libertad del presente se sitúa ya por encima de la materia" (Lévinas, 1979, p. 44).

Pero se trata de señalar aquí sobre todo lo que este primer Lévinas, todavía en busca de su conceptualidad, anticipa sobre la muerte. Se nos invita a que sobre ella no vayamos a aprender a las academias existencialistas. Sino a Shakespeare. En un cierto momento, el autor parece esbozar un gesto de autocrítica: tal vez ha "abusado" de sus referencias al dramaturgo. Pero no. En la estela de un cierto Kierkegaard, Lévinas se pronunciará con esta contundencia: "Pero me parece a veces que toda la filosofía no es sino una meditación de Shakespeare" (Lévinas, 1979, p. 60).

Romeo y Julieta, Macbeth, y, sobre todo, Hamlet ("la tragedia de la tragedia"), enseñan dramáticamente que la muerte no es simplemente algo así como la nada. No habría drama si morir fuera "simplemente" sumergirse en el no ser, y en ese sentido, una "liberación". La doctrina Lévinasiana del "il y a", elaborada por primera vez en De la existencia al existente, pone en graves dificultades a esa 
mirada tranquilizadora. El existir sin existente, que Heidegger había "elevado" a nuevo paradigma de la trascendencia (la trascendencia del ser sobre el ente), se concreta en la cotidianidad como el anónimo "hay". Y "el" problema con el "hay" es que no hay manera de "evadirse" de él. (Y se recordará que poco antes de la Catástrofe Lévinas había escrito un ensayo premonitorio titulado De la evasión). Lo absurdo último del ser no es la nada, la muerte, o que el ser sea finito. Lo absurdo, "lo malo" incluso, no sería la experiencia de la nada (Heidegger), sino la imposibilidad de evadirse del ser, del "hay" anónimo. Podría aducirse: queda la escapatoria del suicidio. Éste sería una forma de dominio sobre el ser, un último recurso contra el absurdo. El grito de Julieta, en el tercer acto de Romeo y Julieta, "Conservo el poder de morir", podría interpretarse como triunfo del héroe sobre la fatalidad del destino (Lévinas, 1979, p. 29). Pero Shakespeare complica la situación en Macbeth, y sobre todo en Hamlet: reflexiona ahí sobre una cierta imposibilidad del suicidio. Las últimas horas de Macbeth, a partir del momento en que lo inverosímil ocurre (el avance del bosque de Birnam hacia el castillo de Dunsinane) atestiguan una verdad general sobre la muerte: ante ésta el viviente pide siempre "otra oportunidad". No se asume nunca la muerte. No va el existente a ella: es la muerte la que viene. Si el suicidio pretende "dominar" la muerte, no es ya que sobre él recaiga una prohibición de profundas raíces, es que es imposible. Ahora el suicidio parece un concepto contradictorio (Lévinas, 1979, p. 61). Hamlet prolonga esta "filosofía":

Hamlet es precisamente un largo testimonio de esta imposibilidad de asumir la muerte. La nada es imposible. Es ella la que habría dejado al hombre la posibilidad de asumir la muerte, la posibilidad de arrancar a la servidumbre de la existencia una dominación suprema. "To be or not to be" es una toma de conciencia de esta imposibilidad de aniquilarse (Lévinas, 1979, p. 61) ${ }^{6}$.

\section{El ser contra la muerte y la voluntad}

Podría seguirse el proceso de pensamiento por el que Lévinas, a partir del evocado combate con el existencialismo en la hora triunfal de éste en el París de la Liberación, alcanza la madurez de una filosofía consecuentemente heterológica. Podría seguirse, en efecto, hasta cierto punto, a través, en especial, de los ensayos de los años cincuenta reeditados en la segunda edición (1967) de Descubriendo la existencia con Husserl y Heidegger (Lévinas, 2005). Esa explicación, que en cualquier caso no cabe aquí, encontraría, sin embargo, un límite esencial: la obra de madurez, Totalidad e infinito (1961) es rigurosamente inderivable de las premisas que, sin duda, la determinan y la condicionan. La novedad irreductible de aquella obra -que, durante decenios, verdaderamente no "trascendió" en los medios filosóficos canónicos universitarios, ni siquiera en Francia, para vergüenza de dichos medios, sordos casi incurables- hay que asociarla a la muy heterodoxa propuesta de vincular el "judaísmo metódico" de Rosenzweig y de Cohen, con una renovación

6 Señalemos al menos una posibilidad interpretativa ulterior de Hamlet, no contemplada en El tiempo y el otro, pero asociable al concepto, ampliamente elaborado por el último Lévinas, de responsabilidad por el otro, en la instancia de la muerte de éste. El príncipe melancólico da voz al imposible duelo, y dramatiza la "verdad universal" inscrita en el asedio (la hantise diría Derrida) del superviviente asaltado por las "reclamaciones" de los espectros. Que claman siempre, de una manera u otra, justicia. El presentismo de la Ontología nunca podrá acoger una justicia que requiere, así, una estructura intergeneracional de la intersubjetividad. Por lo demás, al varón filósofo Hamlet se le sigue mejor si se recuerda, como contraste y como complemento, la figura máxima de la mujer filósofa en el dramaturgo: Rosalinda (Como gustéis). 
metodológica de la fenomenología. La tensa estructura retórica del dramático prefacio, que se atreve a invocar el profetismo, y la razonabilísima protesta del filósofo frente al riesgo de arbitrariedad dóxica del profeta ${ }^{7}$, atestigua que el propio autor es plenamente consciente de las dificultades de recepción en el medio universitario, ante las que se arriesgaba una obra como aquella, ique fue encima inicialmente una tesis de doctorado!

En el contexto del novum categorial que implica Totalidad e infinito, como filosofía difícil del héteron, en expresa ruptura -pero reflexionadísima-con la tendencia dominante del pensamiento occidental, desde Sócrates hasta más acá de Heidegger (primado de la ontología sobre la ética, de la totalidad sobre la relación, y del concepto sobre el singular), debemos situar por nuestra parte aquí la "novedad" específica del motivo "ser contra la muerte". Este motivo domina el importante capítulo sobre "La relación ética y el tiempo" de la tercera sección ("El rostro y la exterioridad"). Aunque no se nombra en estas densísimas páginas al autor de Sein und Zeit, apenas podría seguirse esta explicación fenomenológica de la resistencia del ser temporal frente a los poderes de la aniquilación, si no se tiene a la vista el bello combate emprendido en ella contra el tragicismo del Sein zum Tode. Pero también contra el entendimiento del psiquismo como ser para sí. Y, de nuevo aquí Lévinas, para indicar un camino de pensamiento que se aparta abiertamente de los dos fenomenólogos existencialistas de mayor influencia durante decenios, da voz filosófica técnica a la filosofía, digamos "mundana", de Shakespeare. Esa triple "fuente", si cabe

$7 \quad$ Remito a mi ensayo, Peñalver, 1993, pp. 79107. Hoy matizaría la eficacia metodológica que allí atribuía a la distinción estratégica entre los escritos filosóficos y los ensayos talmúdicos. Sobre la dimensión específicamente judía del pensamiento de Lévinas, García-Baró, 2007, pp. 313-363. llamarla así (y aunque ninguno de los tres nombres propios se encuentran en la superficie del texto de estas páginas) deja ver que estamos ante una especie de repetición del esquema de El tiempo y el Otro. Pero elevado aquí a un nivel de conceptualidad filosófica heterológica que las conferencias del 48 sólo podían barruntar.

El primer paso de esta explicación comporta la audacia de sustraer la aproximación a la muerte a un orden categorial presidido por la antítesis de ser y no ser, y consecuentemente, abocado a la alternativa de ser o no ser. "Toda" la tradición filosófica y religiosa ha interpretado la muerte, bien como paso a la nada, bien como paso a otra forma de existencia.

Ahora bien, el entendimiento de la muerte como desaparición o como "viaje", tiene como base empírica sólo la muerte de los próximos, no la propia. De manera "más profunda", se capta la muerte del otro como paso al no-ser, como aniquilación, en la pasión del asesinato: la intencionalidad de éste apunta justamente a la aniquilación, a hacer pasar al otro al no ser. Sin embargo, al otro como otro sólo puedo abordarlo en la conciencia moral, y así, bajo la condición de la prohibición de matarlo. La aniquilación del otro, el paso al no-ser del otro en la pasión del asesinato (o "sobre todo" en la pasión del asesinato, cabría sugerir más allá de la letra de Lévinas aquí, si atraemos a este contexto el gran tema de la responsabilidad del superviviente ante "sus" difuntos) es, ciertamente, una "posibilidad" fáctica del mundo empírico. Pero en ella se aloja la prohibición absoluta de matar: se aloja en ella, y no simplemente se superpone a ella. El "no matar" afecta así al sentido de la "posibilidad" de aniquilar al otro. De manera que, en conclusión, hay que "relativizar" el sentido de "aniquilación", de paso a la nada, 
en relación con la muerte del otro (producida, digamos, "directamente" por ego o no) ${ }^{8}$.

No se trata de romper gratuitamente con el principio tertium non datur. Se busca un "orden" en el que la relativización, o la intramundanidad de la aniquilación del otro en la ocasión de su muerte remita a un sentido del morir que escape a la alternativa ser o no ser.

El caso de la relación con la muerte propia nos permite determinar mejor ese orden. Y en esto, a pesar del sistemático antagonismo de Lévinas frente al patetismo del Sein zum Tode heideggeriano, se reitera aquí un principio metódico del análisis existencial: el primado de la relación con la muerte propia, en todo "saber" de la muerte. Si la dificultad de una alternativa absoluta entre el ser y el no ser aparece ya al abordar la muerte del otro, el "sentido de mi muerte" se contiene en el rechazo de esa alternativa. Cabe verlo, digamos fenomenológicamente, a partir del conocimiento instintivo de la muerte que se aloja en el miedo a la amenaza mortal como tal. Esta amenaza al margen de todo horizonte de expectativa del viviente. La estructural imprevisibilidad de la muerte (ultima latet) impide algo así como una "acogida" de la muerte propia, pero en rigor reprime asimismo una "lucha" contra la muerte, si lucha requiere algún tipo de visibilidad, fuerzas que se confrontan en un terreno común. Estaría aquí la segunda audacia notable de este análisis: se apunta a una analogía entre la trascendencia del otro en la relación ética, y el intervalo de trascendencia desde el que me amenaza la muerte. Ésta viene de la noche hostil, o de una hostilidad nocturna:

8 "El movimiento de aniquilación en el asesinato, tiene, en consecuencia, un sentido puramente relativo, como paso al límite de una negación intentada dentro del mundo. Ese movimiento nos lleva en realidad a un orden del que nada podemos decir, ni siquiera el ser, antítesis de la imposible nada" (Lévinas, 1961, p. 209).
"En la muerte estoy expuesto a la violencia absoluta, al asesinato en la noche" (Lévinas, 1961, p. 210).

Se dirá, se objetará: la anterior "descripción" de relación con la muerte propia generalmente vivida como amenaza imprevisible, análoga así a la hostilidad de la Noche, no debería llevar a la filosofía al personalismo típico de la mentalidad primitiva, que reviste la muerte "natural" de potencias hostiles, o que en general se resiste a la noción de muerte natural. Es interesante notarlo: Lévinas parece reconocer la pertinencia $y$ el límite de este parecido entre la fenomenología de la amenaza de "mi" muerte y la mentalidad primitiva. Dice primero, en efecto: “Como (énfasis mío) en la mentalidad primitiva, en la que la muerte no es jamás natural, según Levy-Bruhl, pero requiere una explicación mágica, la muerte conserva, en su carácter absurdo, un orden interpersonal en el que tiende (yo subrayo) a tomar una significación" (Lévinas, 1961, p. 210). Pero después, el filósofo marca sus distancias respecto de la religión primitiva, o incluso "avanzada": "No se trata, claro está, de introducir la muerte en un sistema religioso primitivo (o evolucionado) que la explique, sino de mostrar, tras la amenaza que aquella lleva consigo en contra de la voluntad, su referencia a un orden interpersonal, cuya significación la muerte no aniquila" (Lévinas, 1961, p. 211).

Entre el momento de la analogía reconocida (a saber, entre la fenomenología de la relación con muerte y la mentalidad primitiva alérgica a toda noción de muerte natural) $y$ el momento de la distancia respecto de la "personalización" de las fuerzas de la muerte en la religiosidad más o menos primitiva, Lévinas invoca dos fenómenos que permiten referir la muerte a un "orden interpersonal", y así, incorporar aquella, a pesar de su fondo de absurdo, a la esfera del sentido. Uno es el médico, que se va a presentar como "un prin- 
cipio a priori de la mortalidad humana", otro, la amenaza de muerte que se experimenta en el miedo a la muerte, como amenaza que se cierne contra mí desde toda voluntad extraña, desde toda otra voluntad. (Motivo registrado en el bello, lacónico, incisivo tout autre est tout autre del último Derrida: cualquier otro es totalmente diferente).

El contexto permite desautorizar de nuevo, pero nunca sobra reiterarlo, las extendidas interpretaciones "blandas" del pensamiento de Lévinas como moralismo edificante. La figura amistosa, ayudadora, del médico, aparece sobre el fondo de una enemistad posible previa, no digamos fundante. (Se diría, por cierto que más allá si es que no en contra de la letra de Lévinas, que el otro primero es el enemigo.) Incluso la relación social con el Eterno ("El Eterno hace morir y hace vivir", cita bíblica incrustada, injertada, se diría, en este análisis del médico) estaría marcada por esa duplicidad original, amigo o enemigo, o acaso amigo y enemigo, de todo otro. El Dasein tiene a gala el solipsismo absoluto en la relación con su muerte, como la posibilidad más "propia", la más propiamente "insustituible": con innecesaria solemnidad el Maestro de Alemania proclamará esto bien sabido, "trivial", de que a nadie le puede representar nadie en la hora de su muerte. Pero en la fenomenología del Lituano, la soledad del moriturus no impide una determinada forma de presencia del otro:

La soledad de la muerte no hace desaparecer al otro, pero se mantiene en una conciencia de la hostilidad y, por ello mismo, sigue haciendo posible una apelación al otro, a su amistad y a su medicación. El médico es un principio a priori de la mortalidad humana (cursiva mía). La muerte se acerca en el miedo a alguien, y confía en alguien. "El Eterno hace morir y hace vivir". Una coyuntura social se mantiene en la amenaza. La muerte no se sumerge en la angustia que la trasformaría en "aniquilación de la nada". En el ser para la muerte del miedo, yo no estoy frente a la nada, sino frente a lo que está contra mí, como si el asesinato, más bien que ser una de las ocasiones de morir, no se separase de la esencia de la muerte, como si la cercanía de la muerte siguiese siendo una de las modalidades de la relación con el Otro (Lévinas, 1961, p. 211).

De las dos propuestas interpretativas que hemos querido cualificar como "audaces" -y se aceptará que ciertamente no se derivan en términos de continuidad respecto de la tradicional "sabiduría" de la serenidad ante la muerte-, a saber, la sustracción de la muerte de la esfera en que todo se divide en ser o no ser, y la referencia de la muerte a un orden interpersonal marcado por la ambivalencia amigo/enemigo, el análisis Lévinasiano pasa finalmente a una tercera determinación del morir. Considerémosla una tercera audacia. La muerte amenaza desde la imprevisibilidad absoluta, y en ese sentido, se sustrae al horizonte de posibilidades del viviente (contra el mítico "poder ser" último del Dasein, contra la fantástica "posibilidad de la imposibilidad" de la finitud o "la muerte comprendida" en la Ontología fundamental). El filósofo comenta bellamente el relato de Edgar Allan Poe en el que el narrador asiste horrorizado al estrechamiento progresivo de los muros en que está encerrado, y ve así venir la muerte inminente, o bien "vive la muerte mediante la mirada que, en cuanto mirada, tiene siempre delante de sí una extensión" (Lévinas, 1961, p. 211). Pero Poe enseña "también" la verdad del ultima latet: el instante de la muerte se mantiene como "instante infinitamente futuro". (Y de hecho el narrador del cuento de Poe sobrevive, vive para contarlo). Al final, la muerte vendrá al viviente, no irá 
el viviente a la muerte: "le dernier bout de chemin se fera sans moi" (Lévinas, 1961, p. 211). Ahora bien, junto a la amenaza, ese instante "infinitamente futuro" que será el de mi muerte comporta una estructura de aplazamiento. En ella se apoya el recurso de la voluntad para resistirse a las fuerzas de la muerte. $\mathrm{O}$ es que la voluntad es esencialmente un ser contra la muerte:

Pero la inminencia es a la vez inminencia y aplazamiento. Aquella presiona, pero también deja tiempo. Ser temporal es a la vez ser para la muerte y tener todavía tiempo, ser contra la muerte. En la manera como me afecta la amenaza en la inminencia, reside mi estar puesto en causa por la amenaza y la esencia del miedo. Relación con un instante cuyo carácter excepcional no reside en el hecho de que se encuentre en el umbral de la nada o de un renacimiento, sino en el hecho de que en la vida ese instante es la imposibilidad de toda posibilidad, sacudida de una pasividad total al lado de la cual la pasividad de la sensibilidad que muta en actividad no imita sino de lejos la pasividad. El miedo por mi ser que es mi relación con la muerte no es, pues, el miedo a la nada, sino el miedo a la violencia (y así se prolonga en miedo al Otro, a lo absolutamente imprevisible) (Lévinas, 1961, p. 212).

La mortalidad no puede separarse, pues, de una pasividad última, o primera -fundante a su manera-, del psiquismo: no puede separarse de la vulnerabilidad que afecta a una voluntad "susceptible de violencia". Desde esa mortalidad concreta, el "pour soi" (y no hace falta en la Francia de 1960 insistir en el nombre propio que domina la escena filosófica, de hecho Lévinas no nombra aquí a Sartre, ya lo sabemos) aparece como resultado de una abstracción: el para sí, esa fantástica causa sui, idealistamente (o angelistamente) ajena a su lado de cosa, está, vellis nollis, desde el principio entregado al otro, y a la violencia del otro.

Podrá decirse quizá: aunque sin duda mi mortalidad es inseparable de una vulnerabilidad ante la violencia del otro, el análisis de Lévinas atribuye un peso "excesivo" a la violencia del otro en la relación con mi muerte. (Y quizá la alergia típica del filósofo académico corriente a esta heterología venga a ser finalmente una alergia a la afición "desmedida", dirán, del Lituano al tropo hipérbole). Es el momento de indicar que "violencia" tiene en este idioma una desconcertante extensión: además de la violencia que infringe el acero cortante, o la química del veneno, violencia hay también en el hambre y en la sed, y, en general, ya en el cuerpo en la medida en que éste se mantiene entre la salud y la enfermedad. Una vez más: la amenaza de la muerte no es esencialmente amenaza de no-ser, sino amenaza que proviene de una voluntad hostil, aunque siempre secreta, inaprehensible. (Y en relación sobre todo con este motivo, no se dejará de oír el eco del melancólico príncipe danés en los parajes de estas páginas).

Es el miedo a la muerte lo que libera la "verdad" de mi muerte. El miedo a la muerte que es entonces miedo al enemigo desconocido (Enemigo rumor es el título de un poemario de Lezama Lima: se nos impone la asociación), el quasi-instintivo miedo a la muerte, y no la angustia ante la nada.

Una última asociación, y audaz de nuevo -por seguir con este nuestro empeño en que se advierta el novum inquietante de este idioma-, la asociación aquí de Dios y del enemigo que no forma parte de mi mundo (Lévinas, 1961, p. 212), confirma que la muerte, incluso o sobre todo si vivida como enviada por el Eter- 
no, es indisociable de la violencia. Pero da ocasión también de revelar en la muerte, en la relación con la muerte del otro y con la mía, la posibilidad de un sentido: un "mundo cruel", pero "a la escala de las relaciones humanas" (Lévinas, 1961, p. 213). Antes de la muerte, la voluntad, en su ser contra la muerte, tiene tiempo: por ejemplo para desear al Otro, y así, de "encontrar un sentido, a pesar de la muerte” (Lévinas, 1961, p. 213).

Si la muerte es un problema, o hasta "el" problema, la solución es: tiempo, más tiempo.

\section{Las responsabilidades del superviviente}

Las lecciones sobre "La muerte y el tiempo", dictadas por Lévinas durante el año universitario 1975-1976, y editadas juntamente con un curso impartido paralelamente sobre "Dios y la onto-teología" por Jacques Rolland, deben situarse consecuentemente en la fase última de la trayectoria intelectual del filósofo. Debemos intentar entender esas lecciones, así, en relación con lo que muy claramente se presenta como rasgo diferencial mayor de ese giro notable en el curso de un itinerario, que sin duda mantiene, como suele decirse con cierta inercia, una "profunda unidad", pero que fue largo, y abierto a inquietudes y novedades, surgidas unas de la dinámica interna del programa filosófico heterológico, venidas otras de fuera ${ }^{9}$. Formulariamente, el giro metódico de la filosofía de Lévinas perceptible desde algunos escritos de los finales sesenta, y que alcanza su máxima expresión en Autrement qu'être ou audelà de l'essence (1974), reside en la tentativa formal de abandono del

9 Puede documentarse que la inquietud mayor de procedencia externa, que lleva a Lévinas a revisar su pretensión de "usar" el lenguaje ontológico para exponer el pensamiento heterológico, es la gramatología de Derrida. Remitimos a los ensayos incluidos en la segunda parte de Peñalver, 2000. lenguaje ontológico - al que la heterología de Totalidad e infinito recurría todavía-. El tema mayor será ahora una radicalización del motivo de la responsabilidad para con el otro, ligada a la interpretación de la subjetividad como "sustitución": una tesis que, creemos, rompe, u obliga a romper, con la exposición del psiquismo como "separación" y como “ateísmo", esencial en el libro de 1960.

Un cierto "primado" metódico de la muerte propia, en la estrategia de aproximación al saber de la muerte como el enemigo desconocido o nocturno, se imponía en el análisis de Totalité et infini, no quita que en todo caso a mucha distancia del delirio solipsista del Sein zum Tode. Cabe subrayarlo ahora para indicar el contraste de lo que, novedosamente, plantean estas lecciones: no digamos "primado" de la muerte del otro, pero sí relevancia filosófica irreductible de la responsabilidad de superviviente en toda muerte del otro, responsabilidad por éste "en lo desconocido". Esta responsabilidad del superviviente por y ante la muerte de cualquiera (que a una cierta sensatez podrá parecer "loca", o cuando menos patológica) estaría ligada a la deslegitimación radical de la forma "intencionalidad" en la relación con la muerte del otro. Ahí no habría intencionalidad (que remite al saber y al ser, a la "ontología" ahora puesta radicalmente en cuestión, en cualquier caso más radicalmente que en la fase canónica de la Heterología, en Totalité et infini), sino una afectividad sin intencionalidad (Lévinas, 1993, p. 26) ${ }^{10}$.

La sustracción de la muerte, la del otro como la propia, al ámbito de la intencionalidad, el saber y el ser, permite, en la estrategia general de estas lecciones, conectar con un aspecto que se impone en la "afectividad emocional" ante la muerte, en las lágrimas: el choque con el sin-sentido de la muerte. En esta conside-

10 Anotemos que Lévinas apela aquí al Michel Henry de L'Essence de la manifestation. 
ración cobra cuerpo una "deferencia para con el sin sentido de la muerte". Pero este sinsentido está en el centro de la relación entre lo Mismo y lo Otro, es decir, del tiempo. Es que el tiempo es o sería "la inquietud de lo Mismo por el Otro, sin que lo Mismo pueda jamás comprender al Otro, englobarlo" (Lévinas, 1993, p. 29). Así, la muerte, la propia y la del otro - pero en relación con la del prójimo, la pura interrogación ante lo desconocido está de entrada marcada por la responsabilidad propia del superviviente- nos concierne como un sin-sentido ante el que en rigor no cabe respuesta, no al menos desde el saber, la intencionalidad y el impulso del conatus. Esa pura interrogación ante lo desconocido, propia del presentir el morirse uno y del ver morirse otros, es ya una modalidad de la relación con lo más allá del ser.

La segunda de las lecciones ("La muerte del otro y la mía"), cuya significación metódica hemos querido registrar en lo anterior, concluye con una serie de "presupuestos", constructivos unos, polémicos otros. Constructivo $y$ polémico es el quinto, al que cabe atribuir, en el desarrollo de las lecciones que ya no vamos a poder seguir aquí, una significación operatoria decisiva: "El esse humano no es primordialmente conatus, sino rehén, rehén del otro".

Se puede entender por qué, desde la apertura del curso, Lévinas anuncie que su propuesta lleva a una "discusión con Heidegger".

Podrá decirse, desde la letra de Heidegger, que, ciertamente, el conatus no parece relevante como estructura del Dasein. Y sin embargo, en un cierto momento de la lectura, tras la famosa angustia ante la nada, el análisis presuntamente neutral, ontológico, de Heidegger, dejaría ver la decisión existencial del filósofo, más o menos vellis nollis: la decisión de proyectar en el Dasein el impulso al ser, el empeño en ser. Y ese conatus presenta su figura más característica en la voluntad viril de los guerreros, en el ser para la muerte del héroe ${ }^{11}$.

Se entiende que en el contexto de este curso, a cuya significación general deberemos volver más despacio en otra ocasión, se salude con tanta "simpatía" el gran pasaje de la Fenomenología del espíritu sobre Antígona, sobre la "verdad" de la inhumación (Lévinas, 1993, p. 99 y ss). El filósofo por antonomasia de la razón de Estado ("bête noire", y con fundamento, del Lévinas de Totalidad e infinito) se deja seducir en un cierto momento por la "ironía femenina", y por la piedad familiar que, contra los intereses y la racionalidad de un Creonte instaurador del orden en la polis, insiste en entregar a la tierra maternal los restos mortales de los queridos.

\section{Referencias}

Adorno, T. W. (1975). Dialéctica negativa. Madrid: Taurus.

11 En 1920 se publica el primer volumen de los Ensayos sobre sociología de la religión (trad. esp. de J. Almaraz y J. Carabaña, Madrid, Taurus, 2001). Muy verosimilmente Heidegger debió leer la célebre Zwischenbetrachtung que se incluye al final de ese volumen ("Teoría de los estadios y direcciones del rechazo religioso del mundo"). A propósito de la esfera política, y en especial a propósito de la "ajenidad" de dicha esfera a la tendencia acósmica de la religión del amor, Weber invoca la guerra: la comunidad del ejército sobre el campo de batalla, la comunidad en relación con la muerte, es "la comunidad más grande de todas". Sólo en el marco de esa comunidad política de la nación en guerra, la muerte podrá tener "sentido", ser muerte "por algo". Obviamente, el recuerdo de este pasaje, en relación con la escritura de Sein und Zeit, no pretende, insensatamente, desvirtuar la lógica interna del análisis heideggeriano. O sugerir una "influencia" formal del sociólogo en el fenomenólogo de Friburgo. Pero sí puede poner en la pista de un contexto relevante de lo que hemos llamado decisión existencial previa de la Ontología fundamental. 
Aristóteles. (2002). Ética Eudemia. Carlos Megino (tr.). Madrid: Alianza.

Derrida, J. (2001). Chaque fois unique, la fin du monde. Paris: Galilée.

García-Baró, M. (2007). La compasión y la catástrofe. Salamanca: Sígueme.

Henry, M. (1963). L'Essence de la manifestation. París: PUF.

Landsberg, P. L. (1999). Ensayo sobre la experiencia de la muerte. El problema moral del suicidio. Madrid: Caparrós.

Lévinas, E. (1961). Totalité et infini. Salamanca: Sígueme.

Lévinas, E. (1996). Nouvelles lectures talmudiques. Paris: Minuit.

Lévinas, E. (1993). Dieu, la mort et le temps. Établissement du texte, notes et postface de Jacques Rolland. Paris: Grasset.

Lévinas, E. (1979). Le temps et l'autre. Paris: Fata Morgana.

Lévinas, E. (2005). Descubriendo la existencia con Husserl y Heidegger. M. Vázquez (tr.). Madrid: Síntesis.

Lévinas, E. (2000). De la existencia al existente. Madrid: Arena Libros.

Lévinas, E. (s/f). Algunas reflexiones sobre la filosofía del hitlerismo.

Mardones, Reyes Mate, (Eds.). (1998). Judaísmo y límites de la modernidad. Barcelona: Riopiedras.
Martínez Marzoa, F. (1999). Heidegger y su tiempo. Barcelona: Akal.

Peñalver, P. (1987). Márgenes de Platón. Murcia: Universidad de Murcia.

Peñalver, P. (2000). Argumento de alteridad. Madrid: Caparrós.

Peñalver, P. (2006). Ironies de l'essence. Lévinas et Sartre: deux aventures de la responsabilité moderne. En Cahiers d'Études Lévinassiennes, 5.

Peñalver, P. (1993). El filósofo, el profeta, el hipócrita. En Isegoría, 7.

Rosenzweig, F. (1997). La estrella de la redención. Miguel García Baró (tr.). Salamanca: Sígueme.

Savater, F. (2000) Diccionario de filosofía. Madrid.

Spinoza, B. (1987). Ética. Vidal Peña (tr.). Madrid: Alianza.

Sucasas, J. A. (2004). Emmanuel Lévinas (1906-1995): el absoluto ético. En Moisés Barroso y David Pérez Chico (Eds.). Un libro de huellas. Aproximación al pensamiento de Emmanuel Lévinas. Madrid: Trotta.

Platón. (1986). Diálogos, III. Madrid. Gredos.

Weber, M. (2001). Ensayos sobre sociología de la religión. J. Almaraz y J. Carabaña (tr.). Madrid: Taurus. 